\title{
ОСОБЕННОСТИ ПРОСТРАНСТВЕННО-ТЕРРИТОРИАЛЬНОГО РАЗВИТИЯ РЕГИОНАЛЬНЫХ ПРОМЫШЛЕННЫХ КОМПЛЕКСОВ В УСЛОВИЯХ НОВОГО ТЕХНОЛОГИЧЕСКОГО УКЛАДА *
}

\author{
(c) 2020 Байзулаев Салих Ахметович \\ кандидат экономических наук, доцент кафедры «Экономика и финансы», \\ заведующий кафедрой «Экономика и финансы» \\ Кабардино-Балкарский государственный университет, Россия, Нальчик
}

() 2020 Ягумова Зарема Нурбиевна

кандидат экономических наук, доцент кафедры «Экономика и финансы» Кабардино-Балкарский государственный университет, Россия, Нальчик

E-mail: zarema262@mail.ru

(c) 2020 Гергова Залина Хусеновна

кандидат экономических наук, доцент кафедры «Экономика и финансы» Кабардино-Балкарский государственный университет, Россия, Нальчик

(c) 2020 Гузива Лейла Межгитовна

кандидат экономических наук, доцент кафедры «Экономика и финансы» Кабардино-Балкарский государственный университет, Россия, Нальчик

В статье рассматривается возможный комплекс мер, направленный на адаптацию регионов к новым условиям модернизации промышленности и внедрению технологических инноваций; исследуется необходимость организации рационального пространственного размещения производства в условиях нового технологического уклада, поскольку это является одним из условий устойчивого развития государства.

Ключевые слова: промышленность, развитие регионов, пространственно-территориальный потенциал, инновации, устойчивый рост.

Совершенствование управления развития региональных промышленных комплексов в условиях нового технологического уклада целесообразно рассматривать во взаимосвязи с особенностями пространственного развития территорий. Возрастание значимости регионов Российской Федерации в повышении эффективности социально-экономического развития национальной экономики способствует актуализации научных исследований в области сбалансированного развития территорий. Необходимо отметить, что неравномерность в развитии регионов характеризует любую национальную экономику, и даже в странах с относительно комплексным хозяйственным развитием, экономическая динамика зачастую свидетельствует о присутствии как отраслевых, так и территориальных диспропорций [1,2].

Существует множество как объективных, так и субъективных причин, порождающих данный дисбаланс. Это различия природноклиматических условий, сложившейся ресурсной базы, воспроизводственной структуры, состояние инфраструктуры промышленных объектов, что можно отнести к объективным причинам. К субъективным же причинам следует отнести неэффективные экономические и политические решения, а также несовершенство методов и инструментов реализации региональной политики.

В настоящее время общепризнано, что изначально социально- экономическое пространство имеет свою многоотраслевую природу и организационно сложную структуру, оказывающую большое влияние на условия жизни человека [4]. Прежде всего, пространственное развитие предполагает систему расселения, систему поддержания инфраструктуры, систему управ-

\footnotetext{
* Работа выполнена в рамках проекта РФФИ 20-010-00451 А Управление региональными промышленными комплексами в целях использования пространственно-территориального потенциала в условиях нового технологического уклада
} 
ления производством и природными ресурсами. Все они находятся в тесной зависимости и под воздействием определенных факторов могут агрегировать свой совокупный потенциал в создании специфики региональной производственной структуры и ее системы жизнеобеспечения населения.

Заботится об организации рационального пространственного размещения производства должно в первую очередь государство, поскольку это является одним из условий устойчивого развития государства. Причем в данном процессе принимают непосредственное участие все государственные институты, потому что их деятельность в той или иной степени имеет отношение к определенной территории. Несмотря на то, что большое внимание уделяется проблеме рациональной организации экономического пространства, все же остаются недостаточно разработанными единые концептуальные основы, которые могли бы позволить интегрировать имеющиеся положения теории экономического пространства в целостную логическую систему. Традиционная парадигма пространственного развития регионов, основанная на приоритете материальных факторов размещения, в условиях нового технологического уклада уже не способна объяснить современные пространственные процессы.

В настоящее время идея технологического прорыва, способствующего экономическому росту регионов страны и гарантирующего их лидирующие позиции в производстве технологически продвинутой продукции, способствовала реализации новых государственных программ, созданию коммерческих и некоммерческих объединений, ориентированных на развитие технологических инноваций и цифровизацию производства

Основным документом, регулирующим переход к новому этапу индустриализации в России, стал Федеральный закон 2014 года «О новой промышленной политике Российской Федерации», в соответствии с которым и региональные органы власти принимают нормативно-правовую базу, регулирующую вопросы технологической модернизации и инновационного развития региональной промышленности.

По мнению многих аналитиков и исследователей новая промышленная революция, сопровождающая собой создание нового типа промышленного производства, основанного на полной автоматизации, технологии интернета вещей, виртуализации пространства и т.д., ставит перед государством и обществом в целом новые сверхважные задачи адаптации и переориентации работодателей на новые требования к профессиональным знаниям и навыкам их работников [3, 6].

Необходимо отметить, что технологическое развитие имеет как положительные стороны, а именно, повышение уровня жизни, что создает новые потребности человека, так и отрицательные стороны - усиление социального расслоения. На наш взгляд, для повышения социальноэкономического потенциала пространственного развития регионов, внедрения передовых технологий в жизнь людей необходимо объединение усилий науки, власти, бизнеса и общества, способных обеспечить согласованное и эффективное решение проблем.

Основными направлениями устойчивого пространственного развития регионов и их безопасного вхождения в новое индустриальное поле мирового пространства, необходимо:

1. Изменение характера отбора перспектив развития. Производственно-отраслевую ориентацию необходимо дополнить определением хозяйственно-организационных и социальноэкономических приоритетов. Данные приоритеты должны быть расставлены на государственном уровне и учитывать как интересы государства в целом, так и интересы населения различных территорий, учитывая соответствующие временные и масштабные параметры.

2. Объединение ресурсов, распределяемых по различным программам и направление их на решение комплекса связанных между собой проблем, что, в свою очередь, позволит сократить затраты на смежные нужды.

3. Создание единой системы, интегрирующей инновационные подходы и технологии (робототехника, 3-D принтеры, огромные объемы данных);

4. Участие российских высококвалифицированных IT-специалистов в разработке инновационных программных продуктов, предназначенных для промышленного сектора экономики.

5. Регулирование профессиональной мобильности с территорий, характеризующихся низкой заработной платой работников, в города, характеризующиеся хорошо оплачиваемой занятостью по одной и той же профессии (решение проблемы разрыва в заработной плате в 
разных регионах).

6. Объединение в рамках пространственного развития населения, бизнеса и власти, в целях содействия эффективному перспективному развитию конкретных территорий на основе максимального использования внутренних возможностей. Пространственный аспект, способствующий достижению взаимодействия и сопряженности интересов всех уровней власти, ведомств, бизнеса, корпораций, территориальных сообществ, предотвратит противоречия и риски. Также возможно ослабление противостояния бизнеса и власти, бизнеса и населения, а также станет затруднительным их сращивание и формирование коррупционных схем.

7. Развитие нестандартного и адаптивного мышления, обеспечивающего адекватное отношение людей к новым технологиям, понимание ими необходимости непрерывного образования.

8. Проведение целенаправленной политики на рынке труда, системное развитие повышения профессионального потенциала.

9. Стимулирование прогрессивных, высокотехнологичных экономических, социальных и экологических процессов с использованием инновационного подхода, что будет способствовать более рациональному использованию пространства и ресурсов государства.
Таким образом, целостная система, интегрирующая различные элементы социальной среды и высокотехнологичного производства, стремящаяся к саморазвитию и реагирующая на быстро меняющиеся потребности, должна стать ядром пространственного развития территорий в новых условиях высокотехнологичных индустриальных преобразований. Чтобы обеспечить экономическое развитие страны за счет новых производственных технологий, мы должны преодолеть цифровой разрыв, инвестируя в цифровые технологии.

При этом, особое внимание должно уделяться лидирующим регионам, способным обеспечить качественный прорыв в передовых технологиях за счет развития своего ресурсного потенциала и создать прочную основу для модернизации производства и инновационного развития промышленности страны.

Таким образом, целостная система, интегрирующая различные элементы социальной среды и высокотехнологичного производства, стремящаяся к саморазвитию и реагирующая на быстро меняющиеся потребности, должна стать ядром пространственного развития территорий в новых условиях высокотехнологичных индустриальных преобразований.

\section{Библиографический список}

1. Байзулаев С.А., Ягумова 3.Н., Гергова З.Х. Стратегическое планирование развития регионального промышленного комплекса. Азимут научных исследований. 2018. Т.7 № 4(25). С. 358-360.

2. Байзулаев С.А., Ягумова 3.Н., Гергова З.Х., Гузиева Л. М. Приоритетные инструменты стратегического управления устойчивым развитием промышленных комплексов. Экономика и предпринимательство. 2017. № 9-2 (86). С. 779-783.

3. Носова С.С., Рябцун В.В., Норкина А.Н. Цифровая экономика как новая модель современного социальноэкономического развития России // Экономика и предпринимательство. 2018. № 3. С. 26-32.

4. Смыслова О.Ю. Готовность регионов к новым вызовам промышленной революции. Вестник Томского государственного университета. Экономика. 2019. № 48. С. 9-28.

5. Смыслова О.Ю., Кокорева А.А. Особенности пространственного развития территорий в условиях новой промышленной революции. Современная экономика: проблемы и решения. 2019. № 5 (113). С. 119-130.

6. Юдина М.А. Индустрия 4.0: перспективы и вызовы для общества // Государственное управление. Электронный вестник. 2017. № 60, февраль. С. 197-215. 